\title{
Stubbornness, perseverance, and tolerance to hardship and trouble: Zhaoqian Liu as a typical Hunan person
}

Received: 25 March 2020. Accepted: 13 April 2021.

doi: 10.21037/prpm-2021-2

View this article at: http://dx.doi.org/10.21037/prpm-2021-2

\section{Introduction}

This is not my first trip to Changsha, the capital city of Hunan Province.

But I'm still very excited when the dishes and drinks of the city come to mind-the rivers seen from the airplane and the signboards at the highway toll station have all reminded me of crayfish.

For people in many provinces, rice is staple food with pepper as a side dish; for people in Hunan, however, the opposite is the case. "When you walk ten steps on a street, you can find a noodles store; when you walk 50 steps ahead, you can find a milk tea house; when you walk 100 steps ahead, you can find a restaurant serving crayfish." The spirit of modern entertainment has become even more popular here.

When I think of the poetic couplet on the front gate of Yuelu Academy, "Only the State of Chu has talented people, and most of them are congregated at this place", I suddenly realize that this place is Hunan, this place is Changsha.

This place is described as magical by Liu Xiaoye, an actress in a stage play, The Life Opinions of Two Dogs: "It's a place with powerful spirit of entertainment, and also a place with philanthropic care for people in the whole world."

\section{"Stubbornness and perseverance": dare to think}

The first line "Only the State of Chu has talented people" is from Yuan Mingyao, who became president of Yuelu Academy (Figure 1) in the Qing Dynasty Jiaqing Period (roughly in the early years of the 19th century). The words originated from an ancient history book (Chronicle of Zuo: the 26th Year of Xianggong): "the State of Chu has many talented people, but they finally come to serve the State of Jin.”

The second line, "Most of them are congregated at this place", were analyzed by Zhang Zhongjie, a student who was studying at Yuelu Academy at the time. The words were excerpted from an ancient book (The Analects

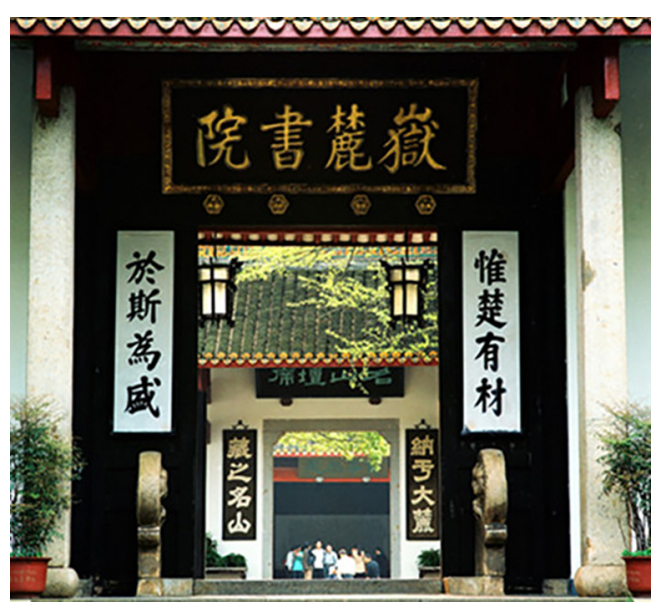

Figure 1 Front gate of Yuelu Academy.

of Confucius [Taibo]): "Many centuries after Tang and Yu, talented people have started to see significant increase in the Dynasty of Zhou."

The general meaning of the poetic couplet is that the State of Chu is a place of many talented people, and here (Yuelu Academy) is a place of congregation for elites.

This is not self-glorification by the academy. There have been numerous stories in history that have demonstrated the stubbornness and perseverance of the Hunan people. According to the book Hunan People and Modern China, in the modern history of China, Hunan province has raised more reformists, military generals, and revolutionary leaders than any other province.

When you take a quick look at Zhaoqian Liu's study and work experience, you can see how he might be a Hunan native. He has deep roots in the province, where he completed elementary and high school education, obtained his bachelor's, master's, and doctoral degrees, and thereafter worked in a local hospital. "I'm locally born and bred in Hunan, and I would devote my whole life to my hometown," says Liu.

A national flag and a commemorative flag for the 70th 


\section{Page 2 of 8}



Figure 2 National flag and a commemorative flag for the 70th anniversary of the founding of the People's Republic of China at Zhaoqian Liu's desk.

anniversary of the founding of the People's Republic of China are raised at a prominent place in his office (Figure 2), and that has demonstrated his firm love to the Communist Party, to the country, and to his career.

"It's not just a slogan or empty talk, it's a principal for our day-to-day work." Zhaoqian Liu holds that is the essence of our education work, "this should be a major part of education beginning from childhood. Without the country and the Party, how can we have a peaceful and stable environment for study and work? Patriotic education is also helpful to improve young people's work attitude and strengthen their team spirit."

When you have correct political principles, you will have the right direction at work. Zhaoqian Liu will keep moving forward if he believes he is doing the right thing, even though "it might be impossible to be successful".

"Chairman Mao Zedong said that revolution is not a dinner party, and there is no place for humility. At that time China was struggling with domestic turmoil and foreign aggression; it was impossible to make the revolution successful without a strong sense of stubbornness and perseverance." In the mind of Zhaoqian Liu, the first consideration is not "whether it's possible to succeed", it is "whether you dare to take a chance". He maintains that the courage to pursue innovations is a further interpretation to
Pharmacogenomics Research and Personalized Medicine, 2021

\author{
湘雅医院2019年度国自项目总数达124项, 位居全国前三 \\ 20198/16 17:00:16

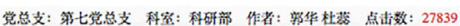

8月16日, 国家自然科学基金委员会公布了2019年度国家自然科学基金项目评审结果。中南大学湖雅医

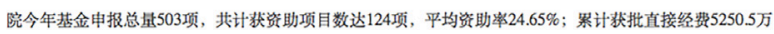

元，较2018年直接经乮4812.5万元增加了438万元。特别可喜的是，湘雅医院国家自然科学基金资助项目总

数再创新高, 在全国医院排行榜榜单中名列第三; 获资助项目数占比中南大学基金项目总数的 $24.6 \%$, 项

目总数和经费总数继续稳居学校各二级单位之首。

Figure 3 Xiangya Hospital received total direct funding of CNY $¥$ 52.505 million from the National Natural Science Foundation for 124 research projects in 2019, the third biggest funding among all hospitals in China.

Xiangya Hospital's culture: strictness, humility, solidarity, and aggressiveness.

On August 16, 2019, the National Natural Science Foundation of China released the results for grant applications in 2019 under the National Natural Science Foundation. Xiangya Hospital secured a total direct funding of CNY $¥ 52.505$ million for 124 research projects, and it was the third year in a row that the hospital received funding support for more than 100 projects. The impressive result put it in the third place among all hospitals in China (Figure 3). Notably, the hospital's Institute of Clinical Pharmacology was awarded 6 grants.

According to Nature Index (www.natureindex.com), a website operated by Springer Nature that gauges the amount of high-quality academic papers produced by every country/region, research institutes, universities and colleges, and industries, Xiangya Hospital ranks 4th in China and 84th worldwide (data timeline: October 1, 2018-September $30,2019)$. It was even more gratifying to learn that Xiangya Hospital was tied in first place among medical institutions in China in terms of the number of articles published in the Nature and Science journals (Figure 4).

The excellent result was apparently the best gift for the new year to Zhaoqian Liu, who is vice president at Xiangya Hospital in charge of scientific research activities. "As we know, clinical practice, teaching, and scientific research are all important, and scientific research is even more important as China is striving to build first-class universities and develop first-class disciplines. In recent years, Xiangya Hospital has taken a lot of actions to strengthen scientific research and innovations through a large vision, large platforms, large teams, large projects, large achievements, and large contributions." These achievements were not easy 


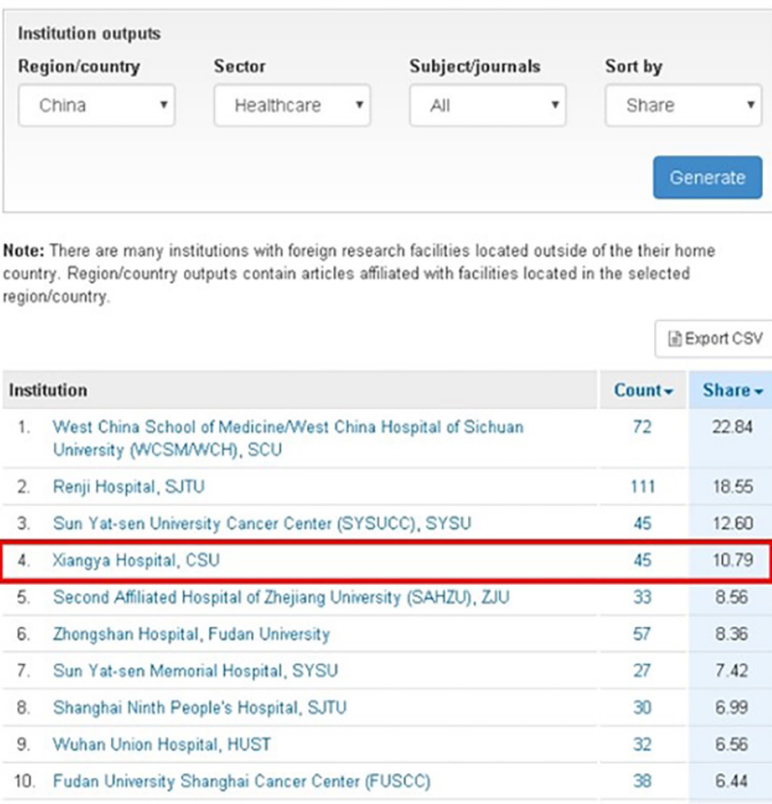

Figure 4 The Nature Index 2019 with Xiangya Hospital came in ranked 4th among medical institutions in China.

to accomplish: "Changsha is a city in the central region of China, and we are unable to get as much resources as our counterparts in Beijing, Shanghai, and Guangzhou. You can imagine how much we have done to get these accolades."

Zhaoqian Liu divides the roles of clinicians into three categories. People who only focus on clinical practice are doctors, those who give considerations to both clinical practice and scientific research are masters, and those who can carry out high-level research work while doing excellent clinical work are generals. "Our patients come from all places across China, and they are seeking help for complicated illnesses; they would not come here just because they catch a cold. Secondly, high-level research is complementary to advanced medical technologies. How can we understand the most advanced medical technology in the world without an in-depth research spirit? In order to master new technologies, our doctors must keep an innovative mindset during research activities. To become leading figures and drive medical development, a general has to be extremely excellent in medical practice and scientific research."

The launch ceremony for the first issue of Pharmacogenomics Research and Personalized Medicine (PRPM) was held on October 12, 2019 (Figure 5). The journal, as an official publication of Xiangya Hospital, would be published

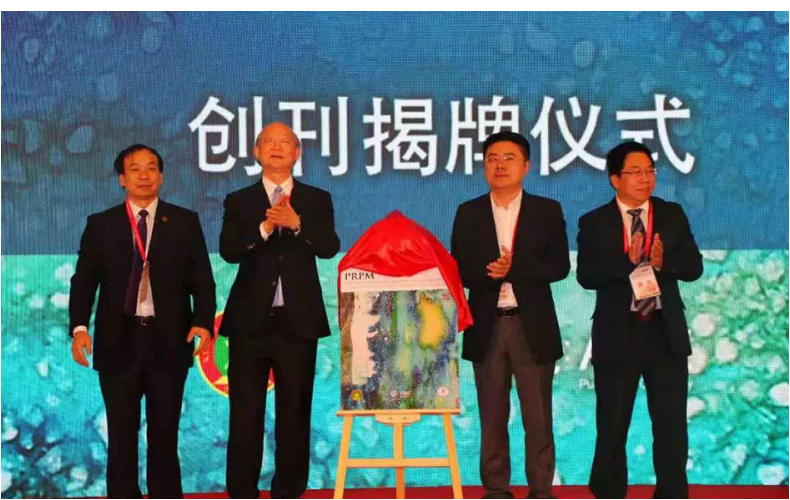

Figure 5 Launch ceremony for the first issue of Pharmacogenomics Research and Personalized Medicine (PRPM) (Prof. Honghao Zhou second to the left, Prof. Zhaoqian Liu first to the left, AME Publishing Company founder Daoyuan Wang second to the right, and Prof. Lizhang Chen first to the right).

by AME Publishing Company. Prof. Honghao Zhou, Prof. Howard L. McLeod from Moffitt Cancer Center and Research Institute, and Prof. Zhaoqian Liu are the editorsin-chief of the journal.

At the ceremony, Zhaoqian Liu voiced his vision for the journal: "We hope the journal will offer an international and comprehensive platform for scholars and medical practitioners worldwide to promote academic exchange in pharmacogenomics and personalized medicine." $\mathrm{He}$ believes PRPM is a result of multiple favorable factors.

"First of all, it's a need of national strategy. Strong science and technology make a strong country. Medical workers like us are duty-bound to make our country stronger. Our hospital has accumulated quite a bit of research experience in recent years, and with the publication of PRPM, we hope Xiangya Hospital can play its role to make China a tech power."

Secondly, as suggested by the title of the journal, Pharmacogenomics Research and Personalized Medicine, Prof. Zhou has devoted his whole life to the research into medication differences among different populations. In an era of translational medicine, we believe it is necessary to tell the world about our team's research achievements in recent decades, and there is still no similar journal in this field.

Finally, the journal is a show of support from our hospital. With a history of more than a century, Xiangya Hospital has been fulfilling its commitment to the elder generations and raising expectations of the younger 
generations. We hope the journal will be guided by the Xiangya spirit and maintain this spirit throughout its history.

When speaking of the cooperation with AME, Zhaoqian Liu said he had been told about the strength of AME in medical publications (some 60 English journals and 13 SCI journals), and its rich experience in publishing medical journals has been noticed by Xiangya Hospital. He insisted that editorial board members should be well qualified and that all the articles published must meet high standards, which is the most important part of being a good journal.

Zhaoqian Liu, who has been vice president of Xiangya Hospital since the Institute of Clinical Pharmacology was combined into the hospital in 2014, stressed that "the first step is to have the courage to find problems. Because there is nothing you cannot do, it's just a matter of whether you have it in mind."

\section{"Tolerance to hardship": dare to do}

According to a map of sleeplessness for Chinese netizens in 2017, Changsha came ranked third, joining in the ranks of Beijing, Shanghai, Guangzhou, and Shenzhen where people generally sleep less. "Changsha people cannot sleep," and Zhaoqian Liu is among them. When Zhaoqian Liu was pursuing a doctoral degree at the start of the 21 st century, he lived in the laboratory for one and a half months and did not return home. "It was a miserable experience. I had a child of only one year old at that time, and it was a hard decision for me to spend all my time on work. Moreover, I was the only person to spend all day and night and live in the laboratory, and it required extreme self-discipline to get through the period of loneliness."

Zhaoqian Liu reckons that sincere enthusiasm for scientific research is the first factor for success, the second factor is passion, and the third factor is a clear goal. Selfdiscipline is the basis for all the factors to work. "Once I went to watch a movie with a friend, and I felt upset after returning from the theater, because a few hours of time had been wasted. After that I made a pledge that I would never put off till tomorrow what should be done today, and I would not go to bed until it's finished. Putting off something to another day is not my personality."

Three of his colleagues and students have talked about Zhaoqian Liu's self-discipline during interviews. Boting Zhou, who was Liu's doctoral student and is now a key member of his medical team, describes his mentor as "vigorous, resolute, and a role model." "He has never put off work to another day. We have a lot of affairs with tight deadlines at the end of the year, and he would work overtime along with team leaders and members to get the work done." Di Xiao, who was Zhaoqian Liu's doctoral student in 2013 and who now works at the hospital's pharmacy department, also speaks highly of her mentor's self-discipline: "He is always the first or second to the workplace, no matter how late he had worked the night prior." Xiangping $\mathrm{Li}$ is also working at the Department of Pharmacy and he has been acquainted with Zhaoqian Liu since 2004. He said he was impressed by Liu's personality and became Liu's doctoral student in 2011. He emphasized that Prof. Liu does speedy and high-quality work and is very responsible: "When I sent my draft graduation thesis to him, he replied less than 24 hours later although he had a busy schedule. He made a lot of revisions, even the punctuation, and I felt very humbled."

When asked whether he can still find the thesis, Prof. Xiangping Li said he needed some time to get the file, because it's been more than four years. A few minutes before midnight, I received a short message from him, saying that he has found that thesis in his mailbox and has sent it to me (Figure 6).

Zhaoqian Liu should be gratified that his personality of self-discipline has been inherited by his students.

Zhaoqian Liu was born in Shuangfeng county, Hunan province. Local people are simple and honest. The county is best known as the hometown of Zeng Guofan, a prominent politician and military general in the late Qing Dynasty, and it's home to about 10 members of the Chinese Academy of Sciences and the Chinese Academy of Engineering. "I'm a son of a native peasant." His father gave him a good name in the hope that he can keep moving forward and have a bright future.

"My father is the first role model in my life", Zhaoqian Liu recalls his childhood. One day when he was reluctant to eat breakfast because there was only rice and no other dishes on the table, his father slapped on his face to give him a lesson about cherishing the hard-earned life.

As the eldest son among five brothers, Zhaoxin Liu felt strongly that he needed get out of the mountainous region and take a look at the world outside. Di Xiao recalls, "Prof. Liu had taken only two leaves, once for a small surgery for himself, and once for his father's funeral. He stuck to work even when his father was terminally ill, and his wife returned to his hometown to take care of his father in the last days." When his father passed away a few years ago, his doctoral students came to help him arrange the funeral. "We 


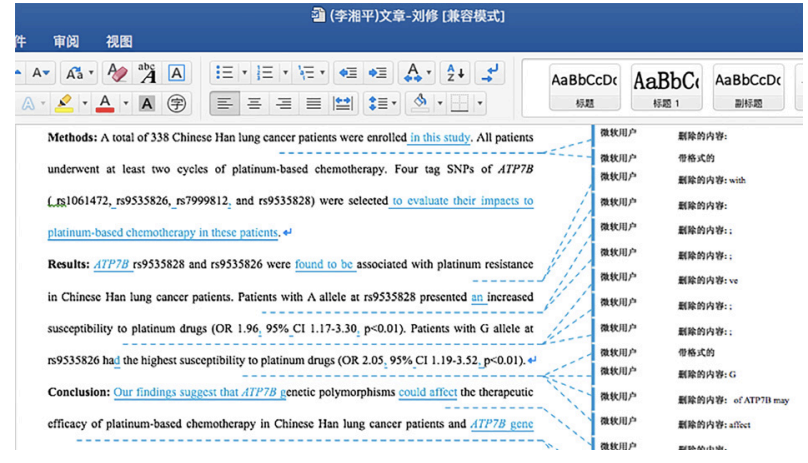

Figure 6 A thesis revised by Zhaoqian Liu for his student Xiangping Li.

know it was a difficult time for him, and we should stand with him and do something to help him," says Boting Zhou.

Zhaoqian Liu entered school at the age of six, and he had to cut firewood after school. These days were very difficult for him, but he was pleased to be able to read books. "There was no electricity at that time, and I would light up the candle and read books for about two hours. I read books every night, because I had a lot of housework to do in the daytime. I love reading very much $[. .$.$] education was not seen as important as$ it's now, and nobody was compelling me to read." Chairman Mao was a role model for him, and he was inspired and encouraged by the stories of Chairman Mao.

"Knowledge makes people powerful, knowledge makes people smart." This is the most important point Zhaoqian Liu has learned from Chairman Mao. It is surprising that Zhaoqian Liu can speak English without any hint of his local accent. "I spent a lot of time to learn English by myself, although there was no English test when I took the national college entrance examination. I was aware very early that I have to master English if I want to go further than other people. I subscribed to the China Daily, and read it every day; I took note of the unknown words and recited them in the morning and evening."

"Chance favors the prepared mind." His diligence paid off during his study in Germany. Despite a limited budget for his research and unsatisfactory laboratory conditions, Zhaoqian Liu published several excellent articles and was praised by his mentor. Germany is still one of his favorite countries. "Their best quality is their attitude toward study. My mentor was very young and only a few years older than me, and that has pushed me to race against time and study even harder. Besides, the experience of studying in Germany has reminded me that China still has a lot to do to catch up

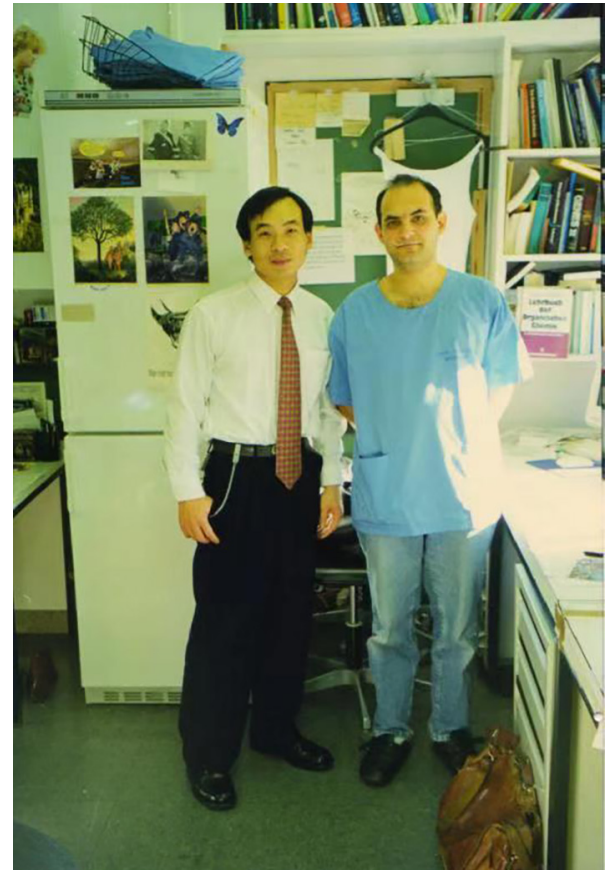

Figure 7 At the University of Munich: Zhaoqian Liu (Left) with his mentor.

with Western countries in medical research, and I have to acquire new skills and put the skills into my everyday work, so that we can narrow the gaps." (Figure 7).

Zhaoqian Liu does not think the study in Germany was painstaking, instead he believes "no pressure, no motivation". The spirit of struggle and sacrifice he developed in Germany has driven him to keep moving forward.

"Energetic" is a common word used by Zhaoqian Liu's three doctoral students to describe him. "He likes sporting activities, and table tennis and badminton are his favorite sports." Xiangping Li speaks highly of Liu's sportsmanship, "every year the provincial federation of education trade unions will hold table tennis competitions, and Prof. Liu is always a key player in the university team." He noted that Liu is not fixed to a certain style when playing sports: "I have played badminton together with him, and I found that he can make a lot of changes in the pitch, and it's hard for rivals to get used to such changes."

Further, Xiangping Li has been impressed by Zhaoqian Liu's "strong desire for victory." "He always said that once you are in the game, you should play seriously. When it turns out to be a very competitive contest, he would never give up and will fight until the last minute."

Zhaoqian Liu holds an opinion that, "when you do 
something, you have to show the courage to try a new method and strive to do the best"; that is to say, think of something that others have not thought of, and do something that others have not done.

\section{“Tolerance to trouble": dare to bear responsibility}

In a Hunan dialect, "tolerance to trouble" means that people should be tolerant and magnanimous to be successful.

Writer Liwei He has classified "Huxiang Culture" into two levels: the first is elite culture represented by the Yuelu Academy, the second is local culture represented by Nanmenkou Street. Pork cooked with chili is a typical example of local culture.

The dish is Zhaoqian Liu's favorite, and the biggest trouble for him during the study in Germany was that he could not eat peppers there. "Peppers were imported from the Netherlands, and I could not afford them." He asked his family to mail red chili powder to Germany, so that he could continue to eat spicy food in a foreign country.

Chili has a history of only about a century in Hunan. Interestingly, Zhejiang, not Hunan, Sichuan, or Guizhou, is the first province to introduce chili into China. Interestingly, chili was brought to China not because of its flavor, but because of its pleasant appearance.

After an arduous journey, chili finally found its place in Hunan. Spicy food in the province has made chili even more popular here.

"Nothing else is important, just spiciness!"

It was said that Guofan Zeng had always chewed chili to refresh himself when he felt tired and sleepy. His army also defeated the rebels for their "tolerance to hardship and willingness to sacrifice their lives".

When asked whether there is any common ground between him and Guofan Zeng apart from the preference for spicy food, Zhaoqian Liu looked a little shy: "I admire him very much, and I have made some trips to his residence. I hope to be as modest and gentle as him, and pay a lot of attention to education like him."

Zhaoqian Liu has spared no effort to help fellow townsmen when they ask for a hand. In his opinion, villagers value hometown feelings very much, and he offers to help them under two circumstances: when they are sick, or when children are seeking further education. "One is related to saving lives, and the other is related to changing a person's destiny."

As an acquaintance with Zhaoqian Liu for many years,
Xiangping Li had dreamed to be his doctoral student, and the dream came true in 2011. "In addition to his academic excellence, I'm deeply impressed by his personality. He is modest and glad to help others." According to Li, Prof. Liu has never rejected any request for help from his friends, or his friends' friends. "His promise is not empty talk. He is offering sincere help to others, and people speak highly of him." (Figure 8).

Xiangping Li recalls that after the Institute of Clinical Pharmacology was combined into Xiangya Hospital in 2014, an anonymous opinion poll was conducted in 2016, with Zhaoqian Liu receiving a large amount of votes. "Colleagues have high opinions of him, and the good opinions are not produced overnight, and are instead accumulated day by day."

As the first doctoral student of Prof. Honghao Zhou, Zhaoqian Liu is fully aware of his responsibilities. The first task is to carry forward Prof. Zhou's academic accomplishments, and the second is to pass them to younger generations. "Unity" and "support" are two words he has frequently used when explaining the tasks. "First, the team must have a team spirit and core values, and that's crucial to passing our knowledge and skills to younger doctors. Second, we have to be united, and that's the case for a country, a school, a company, and even a team, because unity means power. Third, all people should work together and support each other. Finally, expanding the talent base is also important."

This opinion is also held by his doctoral student Boting Zhou. Zhou believes that the leader is crucial to a team and the team's spirit. He says professional integrity is the first value he learned from his teacher, "our team members are following a stringent code of conduct, and when someone is idle, even for a moment, he would quickly return to the right track when he sees other people are working tirelessly."

Zhaoqian Liu's WeChat profile photo is a cartoon figure wearing a white uniform, which was created by $\mathrm{Di}$ Xiao. As the only woman to be interviewed, Di Xiao tells a more emotional story about her teacher. "In addition to our research results, Prof. Liu also pays a lot of attention to our emotional condition. When he notices significant emotional changes in a student, he would ask the student's close friends to talk with him or her and diffuse negative emotions. Besides, he has acted as a successful matchmaker, and urged his students to start a family even several years after their graduation."

One year after Di Xiao received her doctoral degree, 


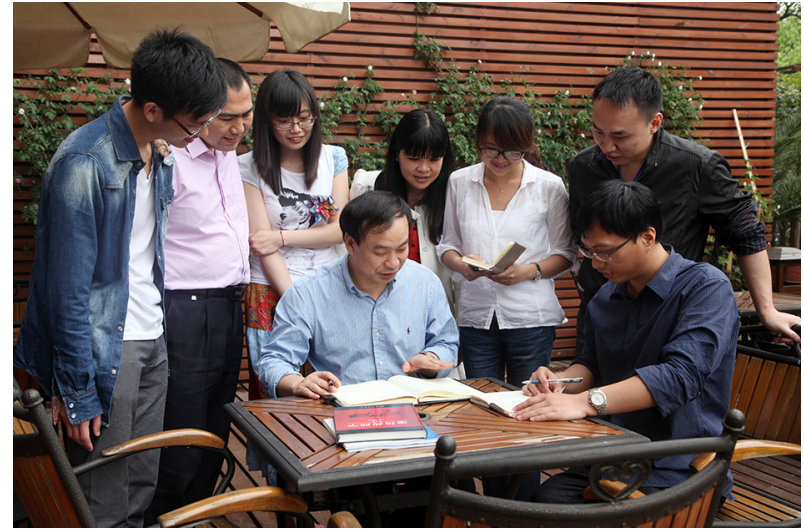

Figure 10 Zhaoqian Liu is a teacher and also a friend to students.

she secured a grant from the National Natural Science Foundation Youth Program, and she still remembers that the first message of congratulation was sent by Prof. Liu. "What surprised and touched me the most was when I took part in the national science popularization explanation competition in 2018, it was a contest unrelated to medical research, but I still received a congratulatory message from him in the evening. At that moment I realized that his care for every student could be felt anytime, anywhere."

"What do you want to say to the young people?" I ask Prof. Liu.

"To be an upright person, a respectable person, and a person with some contribution to society." says Zhaoqian Liu, citing the motto of the Institute of Clinical pharmacology:

Be a good person, do good things, and engage in scholarship.

\section{Epilogue}

"Nothing is too difficult if you put your heart into it.

"One must not be haughty, but not without pride."

Zhaoqian Liu likes these two mottoes most, and they are serving as his life principles.

Stories about Hunan people's stubbornness, perseverance, and tolerance to hardship and trouble have been recorded and witnessed by many people in history.

Not all people from Hunan can become national heroes like Guofan Zeng and Zongtang Zuo, but most of them, including Prof. Zhaoqian Liu, are trying to act like revolutionaries in everyday life.

"How can you say you have no clothes? I will share my robes with you."
Perhaps this might be the biggest hope for Zhaoqian Liu as a connector between the preceding and the following generations at the Institute of Clinical Pharmacology.

\section{Profile}

Zhaoqian Liu, MD, is second-grade professor, a doctoral supervisor, an expert enjoying special allowance from the State Council, a Young and Mid-aged Expert with Outstanding Contributions to National Health and Family Planning, a leader of the National Key Discipline of Pharmacology, and a leader of Key Disciplines with Hunan Characteristics. He is currently a member of the Party committee and vice president of Xiangya Hospital of Central South University, the director of the drug trial institution of the university, chairman of the Academic Committee on Stem Cell Clinical Research, the director of the genomics and pharmacogenomics technology platform of National Clinical Research Center for Geriatric Disorders (Xiangya Hospital), the director of Hunan Province Key Laboratory of Pharmacogenetics, and the director of Hunan Provincial General University Key Laboratory of Pharmacogenetics. He was a senior visiting scholar at the University of Munich, Germany from 1996 to 1997 . He did postdoctoral research in Indiana University School of Medicine from 2002 to 2004, where he won the title of excellent postdoctoral researcher. He also serves as the standing director of the Chinese Pharmacology Society, vice chairman of the Clinical Pharmacology Professional Committee of the Chinese Pharmacology Society, chairman of the Hunan Pharmaceutical Society, vice chairman of the Hunan Pharmacy Association, standing director of the Hunan Medical Association and Hunan Medical Doctor Association, and chairman of the Clinical Pharmacology Professional Committee of Hunan Medical Association.

$\mathrm{He}$ is the deputy editor-in-chief of Chinese Fournal of Biochemical and Pharmaceutics and also the member of the editorial boards of many top journals including fournal of Diabetes Research and Clinical Metabolism, Internal Medicine, Journal of Diabetes and Metabolism, Fournal of Diabetes and Clinical Research, Journal of Cancer Research Update, World Fournal of Respirology, and Genetics and Epigenomics.

He has won many honorable titles including the Yangtze River Scholar and Innovation Team Development Program (by the Ministry of Education), Young and Mid-aged Expert with Outstanding Contributions (by the National Commission of Health and Family Planning), Excellent Talent in the New Century (first batch, by the Ministry 
of Education), Excellent Young Teacher of Colleges and Universities (by the Ministry of Education), Hunan Provincial Natural Science Innovation Research Group, Hunan Provincial "Lotus Scholar Program" endowed professor, Hunan Province's first batch of "121 Talents across the Century", and Young Backbone Teacher in Hunan Province.

He was the principal investigator of 42 national and provincial scientific research projects, which were supported by the National High-tech Research and Development Program (863 Program), the National Science and Technology Major Projects for New Drug Development, the National Natural Science Fund, the Ministry of Education Yangtze River Scholar Innovation Team Funding Program, the Ministry of Education first batch of "Excellent Talents in the New century", and the Hunan Provincial Science and Technology Key Program; in total these grants amount to $\mathrm{CNY} ¥ 40.51$ million. As a key member, he also participated in two NSFC key projects, 3 China Medical Board (CMB) projects, and some other research projects supported by Discipline Innovation and Intelligence Introduction Program of Colleges and Universities and Hunan Provincial Science and Technology Innovation Teams.

He has won 18 scientific and technological achievement awards, including the second prize of National Science and Technology Progress Award, the first prize of the Chinese Medical Science and Technology Award, and the first prize of the Hunan Province Natural Science Award. Also, he has edited and contributed to 17 textbooks and monographs. He has published 351 articles in core journals, including Nucleic Acids Research, Clinical Cancer Research, Clinical Pharmacology \& Therapeutics, Fournal of Clinical Endocrinology \& Metabolism, and Carcinogenesis, among which 248 articles were published in SCI journals. He has filed for 8 national invention patents and won 5 of them.

His main research interests include the basic research and clinical application of pharmacogenetics and pharmacogenomics for major diseases such as diabetes and malignant tumors. He elucidated the novel molecular mechanism of translation and regulation affecting an individual's response to platinum agents, which promotes the change of the traditional view that DNA repair pathway is the core of genome research on platinum drugs and offers a new perspective in explaining the mechanism of individual differences in platinum efficacy. Also, for the first time, he cloned two new $\beta 3$-AR mutation genes: adrb3690 and adrb3-966, which have been included in the Single Nucleotide Polymorphism Database (dbSNP) (rs72655364 and $r s 72655365)$.

\section{Acknowledgments}

Funding: None.

\section{Footnote}

Provenance and Peer Review: This article was commissioned by the editorial office, Pharmacogenomics Research and Personalized Medicine. The article did not undergo external peer review.

Conflicts of Interest: The author has completed the ICMJE uniform disclosure form (available at http://dx.doi. org/10.21037/prpm-2021-2). LL reports that she is a fulltime employee of AME Publishing Company (publisher of the journal). The author has no other conflicts of interest to declare.

Ethical Statement: The author is accountable for all aspects of the work in ensuring that questions related to the accuracy or integrity of any part of the work are appropriately investigated and resolved.

Open Access Statement: This is an Open Access article distributed in accordance with the Creative Commons Attribution-NonCommercial-NoDerivs 4.0 International License (CC BY-NC-ND 4.0), which permits the noncommercial replication and distribution of the article with the strict proviso that no changes or edits are made and the original work is properly cited (including links to both the formal publication through the relevant DOI and the license). See: https://creativecommons.org/licenses/by-nc-nd/4.0/.

(Science Editor: Lili Liao, PRPM, prpm@amegroups.com)

doi: $10.21037 / p r p m-2021-2$

Cite this article as: L Liao. Stubbornness, perseverance, and tolerance to hardship and trouble: Zhaoqian Liu as a typical Hunan person. Pharmacogenomics Res Pers Med 2021. 